NASA Technical Memorandum 102335

\title{
Development and Refinement of Test Bed Simulations
}

N.V. Dravid and D.R. Miller

National Aeronautics and Space Administration

Lewis Research Center

Cleveland, Ohio

A.G. Patterson

Analex Corporation

NASA Lewis Research Center

Cleveland, Ohio

F.J. Gombos

Rockwell International

Rocketdyne Division

Canoga Park, California

Prepared for the

24th Intersociety Energy Conversion Engineering Conference

cosponsored by the IEEE, AIAA, ANS, ASME, SAE, ACS, and AIChE Washington, D.C., August 6-11, 1989 


\section{DEVELOPMENT AND REFINEMENT OF TEST BED SIMULATIONS}

\author{
N.V. Dravid and D.R. Miller \\ NASA Lewis Research Center \\ Cleveland, $\mathrm{OH}$
}

\author{
A.G. Patterson \\ Analex Corporation \\ NASA Lewis Research Center \\ Cleveland, $\mathbf{O H}$
}

\author{
F.J. Gombos \\ Rockwell Corporation \\ Rocketdyne Division \\ Canoga Park, CA
}

\section{Abstract}

Lewis Research Center of NASA (Lewis), with support from Rocketdyne, has been engaged in non real time compuler simulation effort for the Space Station Freedom Eleciric Power System (EPS) [1]. EASY5, a simulation package developed by Boeing Computer Services, Inc. (BCS), is used as the primary tool for this activity. Early in the design of the EPS, two test beds have been set up at Lewis. The Integraled Test Bed (ITB), that combines and upgrades these test beds, is in the planning stage. The test beds are designed to functionally represent many of the components of the EPS and their interconnections. The simulation effort is primarily directed lowards these test heds. Model verification is performed using test bed data.

This paper will present many of the component models, results of simulations, and results of model verification activity.

\section{Introduction}

Lewis was assigned the responsibility to direct the efforts to design, develop, and fabricate the electrical power system for the proposed Space Station Freedom. Rocketdyne Division of Rockwell International Corporation was selected by Lewis as the prime contractor for this effort. It was decided to set up test beds to investigate new concepts in power management and distribution (PMAD), e.g., 20 $\mathrm{kHz}$ distribution, to support the design process. Development of computer simulations of the test beds was underlaken as an important adjunct activity.

While it is desirable for the simulation to precede the test bed hardware design and installation, the two activities took place almost concurrently for the first two test beds. However, for the ITB the modeling lask was completed ahead of the test bed fabrication. This will help in the evaluation of test bed performance before critical design review.

The availability of test beds during the early modeling phase was critical to determine acceptable levels of model fidelity to yield useful resulis. Since many of the components from the earlier test beds would be conceptually re- peated in the ITB, the task of ITB simulation is greatly simplified.

This paper describes simulations of the test beds and verification of the models using experimental data from the lest beds whenever possible. References are provided for information about test bed details and test bed simulation development.

\section{Test Bed Development}

The evolution of test beds at Lewis began with a components test bed, followed by a systems test bed, and shall culminate with an advanced lest bed, the ITB. Following is a brief description of these test beds. $[2,3,4]$

The PMAD/PV test bed, supplied by General Dynamics Corporation(GDC) in 1987, was primarily built to test 20 $\mathrm{kHz}$ technology components. The test bed consists of 20 $\mathrm{kHz}$ inverters, ac switches, high frequency ( $\mathrm{Litz}$ wire) $440 \mathrm{~V}$, primary distribution cable, $440 \mathrm{~V} / 208 \mathrm{~V}$ iransformers, and three types of load converters to convert $208 \mathrm{~V}$, single phase, $20 \mathrm{kHz}$ ac to a type to meet load requirements. The test bed is set up to evaluate replacements for any of the above mentioned components. The dc source 10 the inverters can either be a power supply or the output of the Solar Array fjeld nearby.

The PMAD Systems test bed was assembled at LeRC from components supplied by Rocketdyne, Westinghouse. TRW, and Allied Signal. The test bed has the following major components: Solar Array Simulator, Solar Dynamic Simulator, $20 \mathrm{kHz}$ main inverter units (MIU), $1200 \mathrm{~Hz}$ to $20 \mathrm{kHz}$ frequency converter, Main Bus Swilching $A$ isembly, MBSA, and Power Distribution and Control Assen)bly, PDCA. The PDCA and the MBSA contain power switching devices capable of implementing overcurrent and differential protection schemes. System related issues such as protection against faults, end-to-end voltage regulation, load sharing among inverters, etc., are being investigated in this test bed.

The ITB represents a two channel power distribution system containing many of the EPS functional components. Initially, dc power supplies will be used as sources to the inverters. Solar Array inpui will follow when array regulators are added. The ITB will have a complete primary and 
a representative secondary distribution system. The test bed will be used to address distribution system design issues such as conducted EMI, efficiency, power availabillty, etc.. Another important feature of this test bed is the hierarchical control architecture which will allow investigation of a variety of methods of power system control.

\section{Simulation Development}

Simulation activities for the EPS began in 1985, with a grant to Virginia Polytechnic Institute \& State University(VPI), to generate a computer model of the PMAD/PV test bed, and continued through Rocketdyne as part of the Advanced Development program. Rocketdyne developed computer models for many of the EPS components while integrating those developed by VPI. Initially, Lewis concentrated on moniloring the task order contracts and exercising the models thus generated. Later, independent modeling activity began at Lewis to support test bed operational issues. Presently, modeling work continues at all the three places. The following briefly describes some of the major components and subsystem models that have been developed.

Mapham Resonan Inverter Model: Developed to simulate the PMAD/PV test bed MIU, the model consists of two inverters, paralleled on the dc inpul side and series connected on the ac output side. This permits voltage control by controlling the phase angle between the individual ac output voliages. The simulation of this inverter is based primarily on modeling the operation of SCR switches as ideal switches (for simplicity). The switch operation is based on clock pulses a1 $20 \mathrm{kHz}$. This model has provided satisfactory information for issues such as output voltage harmonic distortion, and general inverter operation control. [5]

TRW Resonan Unverter Model: This model was developed 10 simulate the PMAD Systems test bed MIU (two inverters in parallel). Each inverter consists of switching elements arranged in a bridge configuration around a resonant circuil. The switches are power transistors, but modeled as ideal switches. A $20 \mathrm{kHz}$ clock is used to control the switch operation. Output voltage control of individual inverters is obtained by controlling the energy being supplied to the resonant circuit. This model also has performed satisfactorily in giving results quite similar to the hardware operation. [6]

Iransmission Line Model: A transmission line model generally consists of lumped parameter elements. The simulation allows for a variety of models depending upon the fidelity requirements and simulation time constraints. On one extreme, the line model consists of 5 sections, connecled in cascade, each section being a lumped element $L$ network to represent one-fifth of the line length. The number $S$ is a compromise between fidelity and reasonable computing time. Depending upon the length of the line, even a single section $\Pi$ network may suffice. On the other hand, when a large system with many states is simulated, it may be sufficient to represent the line without any propa- gation time, i.e., as an equivalent resistance to simulate the line loss. This is true when one is not interested in the very high frequencies associated with a transmission line. [7]

Ac Remole Bus Isolator (RBI)_Model: Developed by Rocketdyne, it simulates all the functions of an intelligent switch with built-in sensing and operating logic. There is a provision to also simulate the device as a closed switch thereby reducing considerably the number of states. This model also includes representation of the Remole Power Controller (RPC), a device capable of inturrupting a circuit faster than the RBI. However, the RPC is a lossy device because it does not have a mechanical relay parallel to the solid state switch. [8]

Load Converler Model: Three types of load converler models have been developed to represent power conversion from $20 \mathrm{kHz}, 208 \mathrm{~V}$, single-phase ac. They are: 1) load converter model to obtain $120 \mathrm{~V} \mathrm{dc;} 2$ ) load converter model to obtain variable frequency, variable voltage ac for loads such as motors; and 3) bi-directional $20 \mathrm{kHz}, 208 \mathrm{~V}$ ac $/ 120 \mathrm{~V}$ dc load converter model for special applications. Load converter models are still evolving because of the changing requirements of the base line design. Some of the models have closed loop controls to regulate output voltage/frequency for variable loads. $[8,9]$

Power_Distribution and Control_Uni_ Model: Also known as PDCU, this represents a subsystem which acts as a mini substation. It consists of RBIs, RPCs, and Transformers, A simple controller model for the PDCU is also available. Another similar model is that of the Main Bus Switching Unit (MBSU) which is functionally similar to a switching station. Presently, the models of both PDCU and MBSU utilize the passive, ac RBI/RPC models. In future, they will be replaced by the active, ac RBI/RPC models which have many built-in sensing and logic functions for fault protection.

Photovollaic Source System Model: A simple model has been developed for the PV Source System which includes the solar array, battery charge/discharge converter, array regulator, and controller. The time response of this system is substantially slower than that of the $20 \mathrm{kHz}$ EPS network. Therefore, the model will mainly be used to study the PV Source System and its interactions with the MIU. It should be noted that this model is undergoing continued refinement to reflect latest available data.

Solar Dxnamic Simulator: A model has been developed for the BRU-F Alternator, which has been proposed as an alternative to the PV source. This model is not presently in use but can be revived if the EPS program necessitates. [1]

Switch-State_Models: Initially, the forward Euler rule for numerical integration was utilized. At times, this resulted in unstable solutions, especially for models which include considerable amount of switching, e.g., inverters, RBI, etc.. Later, Switch-State representation was proposed as a better alternative allowing the use of the BCS Gear, variable time step, numerical integration method (see page 164 of [8] and also [12]). Many of the models have since been converted to this approach. 
Qiher Models: Many other models such as R-L-C loads, transformers, instrumentation, dc RBI, elc. have been developed to meet the requirements of simulation

\section{Simulation Results}

After development, the modeis were exercised to verify their operation. Generally, the simulations were performed as functions of time. These included either cold starts or a steady state operation subjected to a disturbance Although many cases were run, only one representative case for each test bed is shown here as an example. More simulation results can be found in the references given.

\subsection{PMAD / PV Test Bed Simulation}

Figure 5.1 shows a configuration of this test bed for which some simulation results are given. Test bed parameters were used whenever available. Three, paralleled MIUs are connecled to a $100 \mathrm{~m}$ cable, feeding into a $4.84 \mathrm{~kW}$ resistive load and a dc load converter supplying a resistive load. The simulation begins with zero initial conditions and the system is brought to a steady state. The load converter load is doubled to $2 \mathrm{~kW}$, as a step, to create a disturbance. Resulting changes in the MIU output voltage, the line current, and the load converter response are shown. The load converter and system responses appear satisfactory. [10]
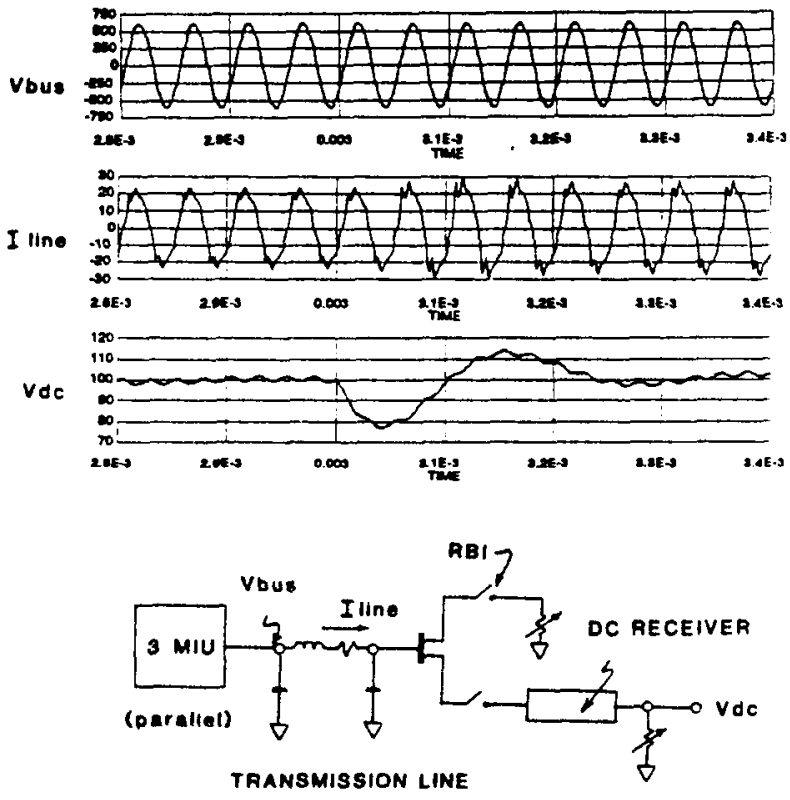

Figure 5.1: Simulation Example for PMAD I PV Test Bed

\subsection{PMAD Systems Test Bed Simulation}

The PMAD Systems Test Bed model was developed to investigate the response of a distributed system to a variety of disturbances, e.g., varying load profiles, network topology changes, faults,etc.. The test bed simulation was also intended to focus on the TRW MIU and to provide subsystem level information such as inverter load sharing, load change response, fault response, etc..

For MIU subsystem analyses, only a small part of the test bed model was utilized as shown in figure 5.2. The distribution network is represented as a transmission line supplying a resistive load. Step load changes are applied one millisecond apart; the first step is from $4 \mathrm{~kW}$ to $8 \mathrm{~kW}$ while the second being its reverse. Plots of inverter output voltage and current are shown.

This type of simulation provides information about the TRW inverter response to load changes which, in turn, can be used to design voltage control loop for optimum performance. [6]

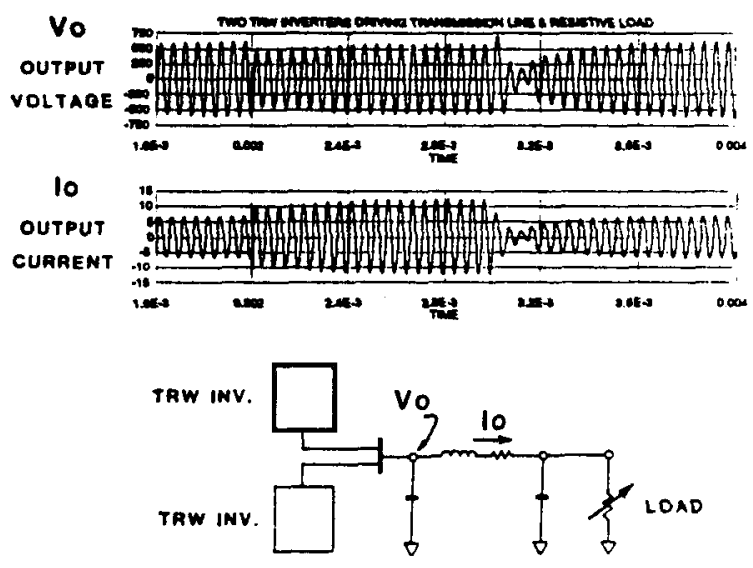

Figure 5.2: Simulation Example for PMAD Systems Test Bed

\subsection{ITB Simulation}

Simulation of the complete ITB system presented a challenge due to the limitations of the computer resources. The large number of states associated with the ITB simulation require excessive amounts of execution time. Some economies were realized by using the simplest form of transmission line model (see section 4). Therefore, the ITB simulations are limited to a demonstration of steady state operation to rule out hidden programming errors. However, subsystem simulations for the ITB were performed with applied disturbances. Figure 5.3 shows a schematic of the ITB system including the hierarchical control system and data network. It must be noted that the PDCU and MBSU blocks contain many RBI/RPC models and, thus, have large number of states. The figure also shows representative bus voltage plots, labeled as $V 1$ and $V 2$, from the two separate, nonconnected rings. These plots show the almost identical waveforms for corresponding quantities. The phase angle differences are due to those between the respective sources. For other simulation results of the ITB, please refer to $[8]$. 

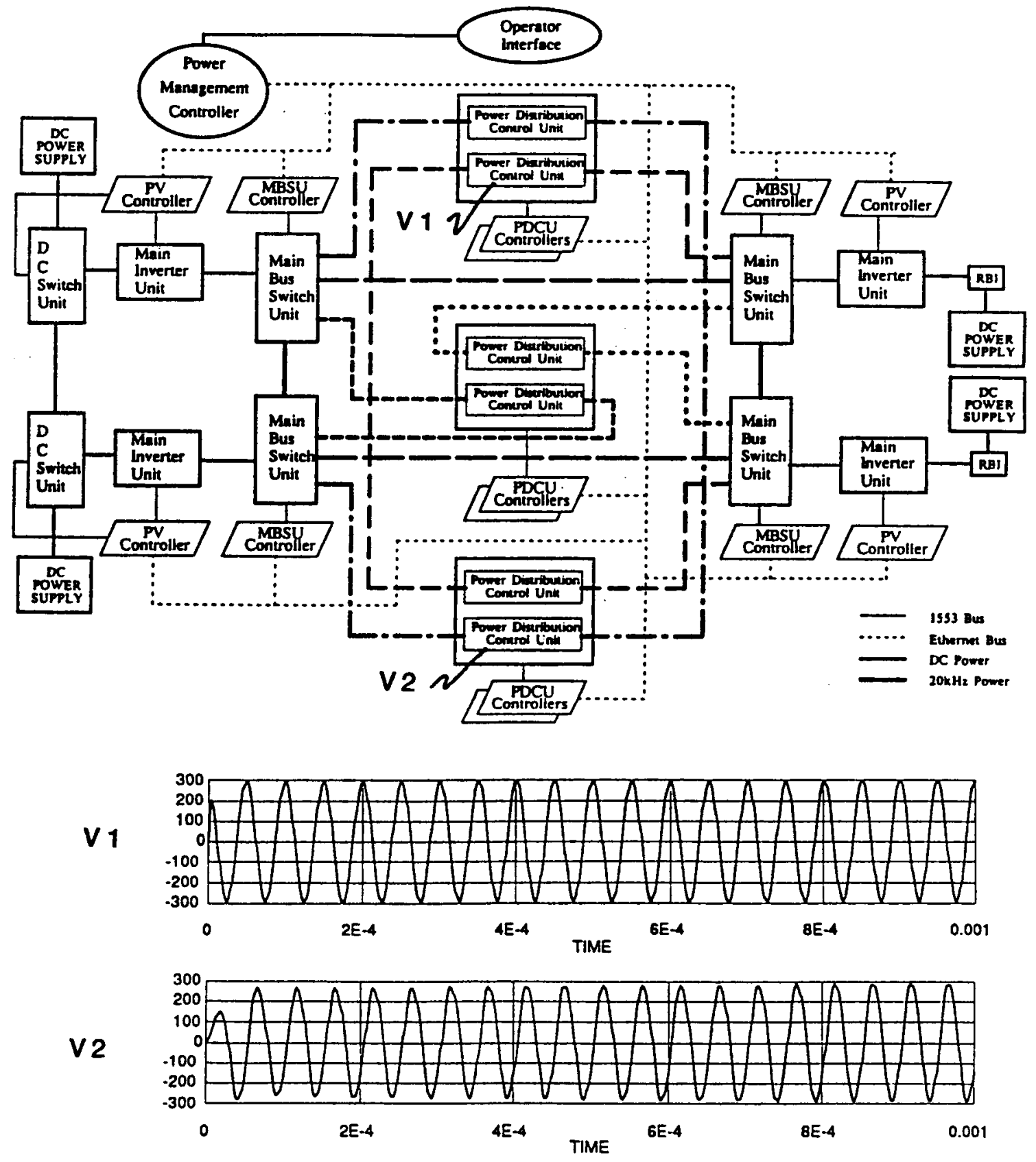

Figure 5.3: PMAD ITB Configuration and sample Simulation results

\section{Simulation Verification from Test Bed Data}

As noled before, the need for verification of the models from test bed data is paramount. These data could come in different forms. Comparing time function plots from the test bed to corresponding plots from the simulation is the time honored approach. However, due 10 limitations of model fidelity, such comparisons are likely to show some mismatch. Nevertheless, such a comparison will be shown. Another method of verification is comparison of derived data from steady state operation of the model and the test bed. This is likely to yield closer comparison even with the limitation mentioned earlier. Some of these are also shown. For more information, please refer to $[5,10]$. 


\subsection{Total Harmonic Distortion (THD)}

Due to the existence of many power processing devices, control of generated harmonics will be a significant issue for the EPS. Therefore, the amount of total harmonic distortion is an important specification for the design and performance of the EPS. Harmonic distortion from the MIU is, among other things, a function of the ratio of clock to resonant frequencies (fsn). Experiments were performed on the PMAD/PV test bed to determine this function. The same was repeated using the test bed model. Figure 6.1 shows the comparison of the results. $[5,10,11]$

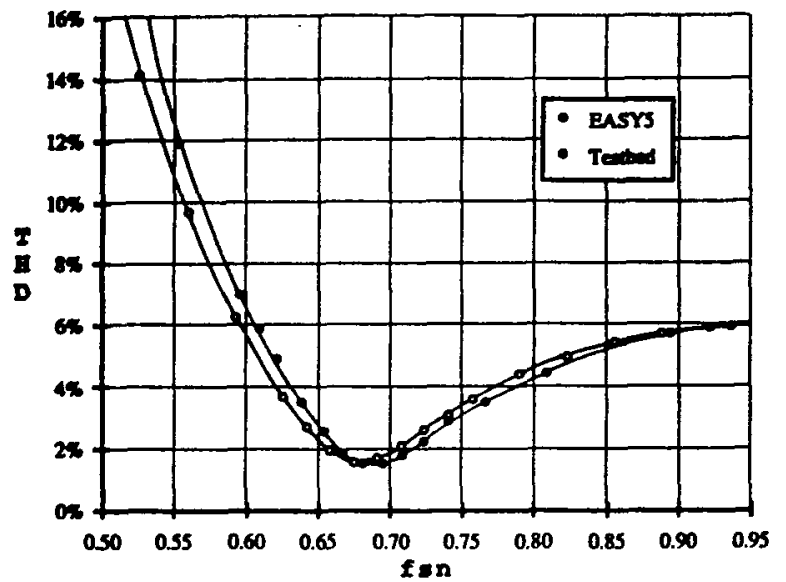

Figure 6.1: Comparison of THD

\subsection{MIU Input Characteristics}

A Mapham inverter, when connected to a PV source, may have an unstable operating point due to the nonlineas voltage-current characteristics of each device. In order 10 investigate this phenomenon, input characteristics of the inverler were experimentally found from the test bed and and also delermined by simulation. Figure 6.2 shows the comparison. [10]

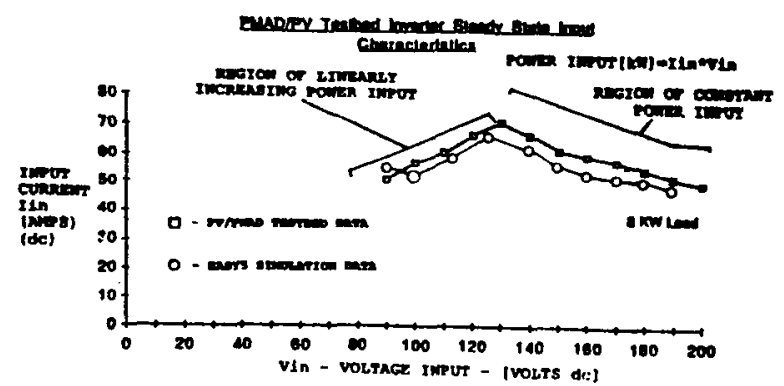

Figure 6.2: MIU Input Characteristics

\subsection{Inherent Voltage Regulation of Inverter}

Looking back from the $20 \mathrm{kHz}$ side, the inverter should appear as any other ac source with some amount of output impedance. Such a source must inherently exhibit voltage regulation, i.e., the output voltage must decrease with increasing power output. Figure 6.3 shows comparison of the voltage regulation characteristics of a Mapham inverter as obtained experimentally and from simulation. [10]

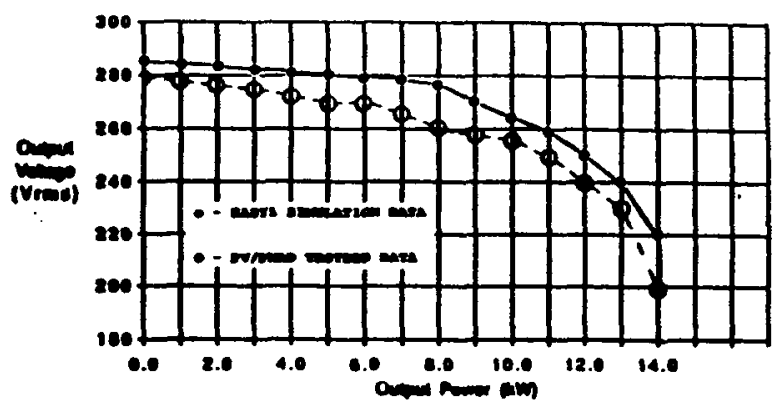

Figure 6.3: Inverter Voltage Regulation

\subsection{TRW MIU Start-up verification}

The start-up of a TRW MIU is somewhat peculiar because of the nature of the control system presently employed. Since the simulation is supposed to mirror the test bed the control system was also modeled in its present form. Comparison of the MIU start-up characteristics is shown in figure 6.4 which verifies the fidelity of the models. [6]

INVERTER OUTPUT VOLTAGE
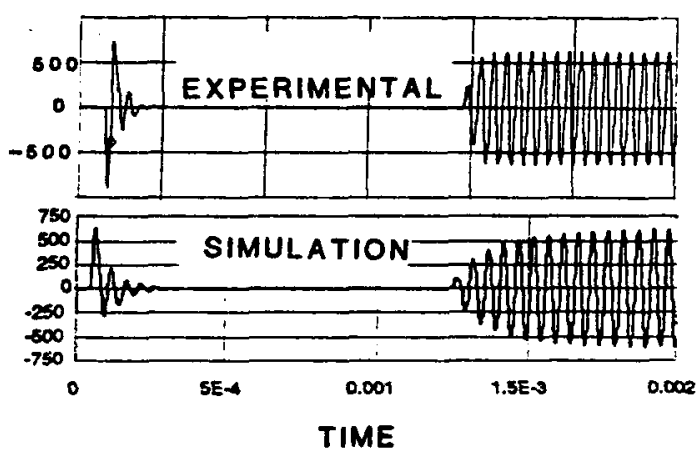

Figure 6.4: TRW MIU Start-Up

\section{Conclusions}

Development and refinement of $20 \mathrm{kHz}$ Test Bed simulation for the EPS has been described and the model verification process demonstrated. The high degree of correlation between the test bed data and the simulation results has been shown. Test bed simulations will be performed prior to hardware tests to uncover any hidden problems. Simulations will be substituted where hardware lests are not practical or convenient. [S]

EASY5, as a software modeling tool, has generally performed satisfactorily. However, it has required excessive 
amounts of computer time for certain simulations having a large number of stales. By improving upon the EASY5 software and by selective reduced order modeling, It may be possible to reduce computation time to a reasonable level([12]). Additionally, other software modeling tools will be evaluated and utilized to conduct specific investigations concerning the EPS. [7]

\section{Acknowledgments}

The authors wish to acknowledge the assistance provided by the following in supplying information for this paper.

R. Sundlerg for PMAD / PV test bed data, R. Beach for PMAD Systems test bed data, Dr. Ponlee $\mathrm{Li}$ for the initial model of the TRW inverter power stage, $A$. Peuron for the ac RBI model, and E. Pongracz-Bartha / J. Kidder for ITB simulation results.

\section{References}

1. F J. Gombos and N.V. Dravid, "An Integrated and Modular Digital Modeling Approach for the Space Station Electrical Power System Development", NASA Technical Memorandum 100904, presented at IECEC-88, Denver, Co.

2. R. M. Bution, A. S. Brush, R. C. Sundberg, "Development and Testing of a $20 \mathrm{kHz}$ Component Test Bed", 10 be presented at IECEC-89, Washington, D.C.

3. R. F. Beach, G. L. Kimnach, T. A. Jell, L. M. Trash, "Evaluation of Power Control Concepts using the PMAD Systems Test Bed", to be presented at IECEC-89, Washington, D.C.

4. PMAD Integrated Test Bed Requirements Document, LeRC-900-100, Rev. B, Sept. 30, 1988; prepared by Rocketdyne Div., Rockwell International
5. R. C. Sundberg, A. S. Brush, R. M. Button, A. G. Palterson, "Distortion and Regulation Characterization of a Mapham Inverter", to be presented at IECEC-89, Washingion, D.C.

6. D. R. Miller, "Characterization of the TRW $20 \mathrm{kHz}$ Inverter using EASY5", a preliminary information report under preparation at NASA LeRC

7. N. V. Dravid, "Investigation of Transmission line modeling for EPS using the Electromagnetic Transients Program (EMTP), a preliminary information report under preparation at NASA LeRC

8. Task Order 5, subtask 1 - Final Report, RI/RD89-166, Contract NAS 3-25078, E. Pongracz-Bartha, Rocketdyne, Canoga Park, CA, April 1989

9. F. S. Tsai, F. C. Lee, "Computer Modeling and Simulation of a $20 \mathrm{kHz}$ ac distribution for Space Station", Final Report, February 1988, VPI \& SU, Blacksburg, VA

10. A. G. Patterson, "PMAD / PV Tesi Bed modeling using EASY5", a preliminary information report under preparation at NASA LeRC

11. R. C. Sundberg, A. S. Brush, A. G. Patterson, "Main Inverter Unit Distortion Test Report", NASA LeRC PIR No. 220, November 11, 1988

12. A. G. Patterson, "Comparison of Power System Model Execution Times using Differen1 Integration Schemes in EASY 5", a preliminary information report under preparation at NASA LeRC 


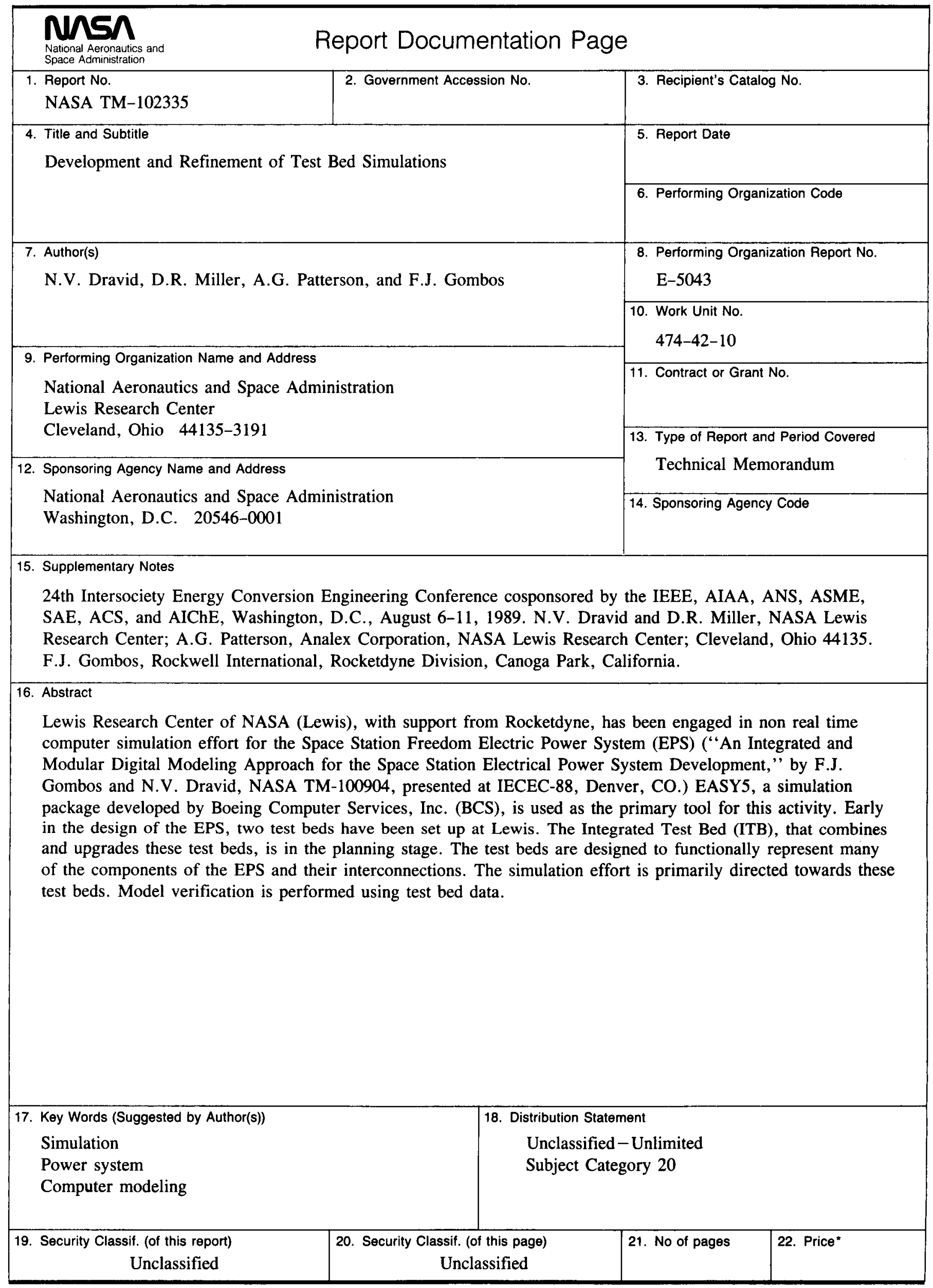

